\title{
Efficacy and safety of the starting position during colonoscopy: a systematic review and meta-analysis
}

\section{(ㄷ)(우우}

Authors

Jun Watanabe ${ }^{1,2}$, Daeho Park ${ }^{3,4}$, Eiichi Kakehi ${ }^{5}, K^{2}$ azuoki Inoue ${ }^{3}$, Shizukiyo Ishikawa', Yuki Kataoka ${ }^{6}$

Institutions

1 Center for Community Medicine, Jichi Medical University, Yakushiji Shimotsuke, Japan

2 Department of Surgery, Tottori Prefectural Central Hospital, Tottori, Japan

3 Department of Community-based Family Medicine, School of Medicine, Tottori University Faculty of Medicine, Yonago, Tottori, Japan

4 Daisen Clinic, 475 Imazaike, Daisen Town, Tottori, Japan

5 Department of General Medicine, Tottori Municipal Hospital, Tottori, Japan

6 Hospital Care Research Unit, Hyogo Prefectural Amagasaki General Medical Center, Amagasaki, Hyogo, Japan

submitted 6.12.2019

accepted after revision 23.3.2020

\section{Bibliography}

DOI https://doi.org/10.1055/a-1149-1541 |

Endoscopy International Open 2020; 08: E848-E860

(c) Georg Thieme Verlag KG Stuttgart · New York eISSN 2196-9736

Corresponding author Jun Watanabe, MD, Division of Community and Family Medicine, Center for Community Medicine, Jichi Medical University, 3311-1 Yakushiji, Shimotsuke City, Tochigi, 329-0498, Japan

Fax: +81-285-44-0628

m06105jw@jichi.ac.jp

\# Supplementary material

Online content viewable at:

https://doi.org/10.1055/a-1149-1541

\section{ABSTRACT}

Background and study aims We aimed to assess the efficacy and safety of the starting position during colonoscopy. Patients and methods We searched CENTRAL, MEDLINE, EMBASE, and the WHO International Clinical Trials Registry Platform through February 2019 to identify studies reporting the comparison between the right/supine/prone/tiltdown and left lateral starting position during colonoscopy. The primary outcomes were mean cecal insertion time and adverse events requiring medication. Two reviewers performed study selection and risk of bias assessment. We determined the quality of evidence using the Grading of Recommendations, Assessment, Development, and Evaluation method. This study was registered in PROSPERO (CRD42019124360).

Results We identified 10 randomized controlled trials (RCTs) (2083 participants), including three trials on right/ tilt-down versus left, two trials on supine/prone versus left, respectively. Mean difference in mean cecal insertion time in supine versus left was $-41.0 \mathrm{~s}$ ( $95 \%$ confidence interval [CI] -57.3 to -24.7$)$ in one study and in tilt-down versus left was $-37.3 \mathrm{~s}\left(95 \% \mathrm{Cl}-72.1\right.$ to $\left.-2.4 ; \mathrm{I}^{2}=58 \%\right)$ in three studies; however, there were no statistically significant differences in prone/right versus left position (very low certainty of evidence). Four of eight studies noted adverse effects requiring medication (moderate certainty of evidence). One RCT applying the tilt-down position was terminated because of increased occurrence of oxygen desaturation.

Conclusion We could not conclusively determine the efficacy and safety of the starting position during colonoscopy because of low certainty of evidence. Further studies are needed to confirm the efficacy and safety of the starting potion during colonoscopy. 


\section{Introduction}

Colonoscopy is recognized as the gold standard method for colorectal cancer screening, polyp surveillance, and diagnosis of lower gastrointestinal symptoms [1]. Colonoscopy is a useful examination that can reduce colorectal cancer mortality [2]. The number of colonoscopies has been increasing [3], and more than 14 million colonoscopies are performed in the United States annually [4]. However, colonoscope insertion, especially in the sigmoid colon, is technically challenging and timeconsuming [5]. Although complications related to the colonoscopy procedure rarely occur, colonoscopy is associated with a colon perforation risk of greater than 1 in 1000 during screening examinations $[6,7]$. Therefore, it is important that the colonoscope is reliably, quickly and safely inserted into the cecum.

A colonoscopy usually begins with the patient in the left lateral position [8], however, there is no evidence supporting the efficacy and advantages of this starting position. When colonoscopy is started in the left lateral position, the air rising from the left side of the colon causes sharp bends in the sigmoid colon and may make it difficult to insert the colonoscope into the cecum. Therefore, a changing in the starting position of the patient during colonoscopy was considered. This would reduce the sharp bends and the cecal insertion time.

The mechanisms by which a starting position other than the left lateral position may facilitate the insertion of the colonoscope have been proposed. When the patient is lying on a starting position other than the left lateral side, the right side of the colon cavity of the sigmoid colon in the direction of colonoscopy is not filled with air, thereby reducing the bowel angulation, fecal residue, and fluid from the direction of colonoscopy, thus potentially easing the passage of the colonoscope [9].

A technically difficult intubation may result in incomplete examination due to time constraints and increased colonoscopist fatigue [10]. Changing the starting position of the patient during colonoscopy is inexpensive and does not burden the patient. However, there has been no systematic review on the efficacy and safety of the starting position during colonoscopy. Therefore, the present review aimed to investigate the efficacy and safety of the starting position during colonoscopy.

\section{Patients and methods}

\section{Protocol and registration}

We registered our review protocol in PROSPERO (CRD42019124360). We prepared and conducted this systematic review following the PRISMA (Preferred Reporting Items for Systematic Reviews and Meta-analyses) guidelines (Appendix 1) [11].

\section{Criteria for considering studies for this review}

Type of studies

We included published and unpublished individual randomized controlled trials (RCTs). We excluded non-RCTs. We included eligible studies irrespective of language, publication data and publication status.

\section{Types of participants}

We included adult men and women (aged 18 years or older) who underwent observational colonoscopy, regardless of the indication (screening, surveillance, or diagnosis). We excluded individuals with a contraindication to colonoscopy, those with previous colonic resection, those with colonic strictures, and those undergoing endoscopic therapy during colonoscope insertion.

\section{Types of interventions}

We included reports on the impact of any starting position other than the left lateral starting position during colonoscope insertion. The intervention was a starting position other than the left-sided during colonoscope insertion performed by colonoscopists or gastroenterologists. We included all studies that used maneuvers for a successful cecal insertion, such as loop reduction, position change, abdominal compression, and variable colonoscope stiffness. We included all studies that used bowel preparation with cathartics such as Senna, Citramag, and/or polyethylene glycol electrolyte solution. We included all studies that used standard colonoscopy equipment with or without a transparent cap or commercially available imagingguided devices but not those that involved balloon colonoscopy.

\section{Types of outcome measures}

Primary outcomes were as follows:

1. Mean cecal insertion time for colonoscopy, defined as the time from the beginning of colonoscope insertion to identification of the base of cecum, as confirmed by the anatomical landmarks, such as the appendicular orifice and/or ileocecal valve; and

2. Proportion of AEs requiring medication, calculated as the number of participants requiring medication divided by the total number of participants.

Secondary outcomes were as follows:

1. Proportion of successful cecal insertion after primary colonoscopy procedure, calculated as the number of successful insertions divided by the number of participants;

2. Proportion of participants who needed a position change from the starting position during colonoscope insertion, calculated as the number of position changes divided by the total number of participants. Position changes were based on the colonoscopist's or participant's preference and were only in the insertion phase;

3. Mean score of the participants' pain or discomfort on a visual analog scale or a numeric rating scale, in which the low- 
est score denotes no pain or discomfort and the highest score denotes unbearable pain or discomfort;

4. Proportion of AEs due to sedatives/analgesics used and procedure-related complications as defined by the authors. The proportion of each AE was calculated as the number of participants who had each adverse event divided by the total number of participants.

We changed the primary outcomes from the proportion of successful cecal insertion and colon perforation to mean cecal insertion time and AEs requiring medication in view of its importance and incidence. We added the mean score of the participants' pain or discomfort as outcome after protocol registration.

\section{Search methods for identification of studies}

Electronic searches

We searched the following electronic databases: CENTRAL (Cochrane Central Register of Controlled Trials), MEDLINE (Ovid, 1946 to February 2019), EMBASE (PROQUEST, 1974 to February 2019), and World Health Organization International Clinical Trials Registry Platform (ICTRP) search portal (Appendix 2).

We searched the references lists of guidelines for studies related to colonoscopy published by the European Society of Gastrointestinal Endoscopy and the U.S.Multi-society Task Force on Colorectal Cancer $[12,13]$. We also searched the reference lists of all retrieved articles for further identification of potentially relevant studies. In cases of duplicate published trials, we considered only the latest or at least the more complete version.

\section{Data collection and analysis}

\section{Selection of studies}

Two of the four review authors (JW and DP, KE or KI) independently screened the titles and abstracts of all studies identified by the search. We discarded studies that were not applicable, but initially retained studies that might include relevant trial data or information. Two of the four review authors (JW and $\mathrm{DP}, \mathrm{KE}$ or $\mathrm{KI}$ ) independently assessed the retrieved full-text versions of potentially relevant abstracts chosen by at least one review author and identified full-text studies meeting the inclusion criteria. We contacted the authors of the studies, if necessary, to evaluate the eligibility for inclusion. We resolved differences in opinion on data collection through a discussion between two reviewers. A third review author (YK or SI) was consulted if necessary.

\section{Data extraction and management}

Two of the four review authors (JW and DP, EK or KI) independently extracted data from the included studies. We resolved any disagreement through discussion. The third review author (YK or SI) served as the arbitrator when a consensus was not reached. We contacted the authors of the studies to obtain further details when necessary. We used data extraction forms to record data from the selected studies.

\section{Assessment of risk of bias in the included studies}

Two of the four review authors (JW and DP, EK or KI) assessed risk of bias as described in the Cochrane Handbook for Systematic Reviews of Interventions for the following six domains: random sequence generation (selection bias), allocation concealment (selection bias), blinding of participants and personnel (performance bias), blinding of outcome assessment (detection bias), incomplete outcome data (attrition bias), and selective reporting (reporting bias). Two authors classified each domain into one of three categories (high risk, low risk, or unclear) [14]. Two authors compared their evaluations and resolved any disagreements through a discussion or by consulting a third review author (YK and/or SI) if necessary.

\section{Measures of treatment effect}

We performed analysis using Review Manager 5.3 (RevMan 2014). We calculated relative risks (RRs) with $95 \%$ confidence intervals ( $\mathrm{Cls}$ ) for the following binary outcomes: adverse events requiring medication and the proportion of successful cecal insertion. We integrated the mean and standard deviation of continuous variables according to the method described in the Cochrane handbook [14]. We calculated the mean difference (MD) with $95 \% \mathrm{Cl}$ for the cecal insertion time for colonoscopy (continuous outcome). We also calculated the standardized MD with $95 \% \mathrm{Cl}$ for the mean score of the participants' pain or discomfort. We summarized all adverse events according to the definition of each study; however, we did not conduct a meta-analysis.

\section{Dealing with missing data}

For discrete variables, we analyzed all the data according to the intention-to-treat concept. We included participants who dropped out in our analysis. For continuous variables, we did not perform imputation of missing values as per the recommendation in the Cochrane handbook [14].

We attempted to contact the authors of the primary studies to request for the missing values whenever necessary. If no reply was obtained from the authors, we classified the data as missing.

\section{Assessment of heterogeneity}

We first assessed heterogeneity through visual inspection of the forest plots and calculated the $\mathrm{I}^{2}$ statistics (I2 $0 \%$ to $40 \%$, may not be important; $30 \%$ to $60 \%$, may represent moderate heterogeneity; $50 \%$ to $90 \%$, may represent substantial heterogeneity; and $75 \%$ to $100 \%$, considerable heterogeneity). When heterogeneity was identified $\left(I^{2}\right.$ statistic $>50 \%$ ), we investigated the reasons for heterogeneity. We quantified heterogeneity using the $X^{2}$ test $(P<0.10$ was considered statistically significant) and $\mathrm{I}^{2}$ statistics. We evaluated heterogeneity using subgroup analysis.

\section{Assessment of reporting biases}

We searched the trial registry (ICTRP) to identify registered but unpublished trials. 


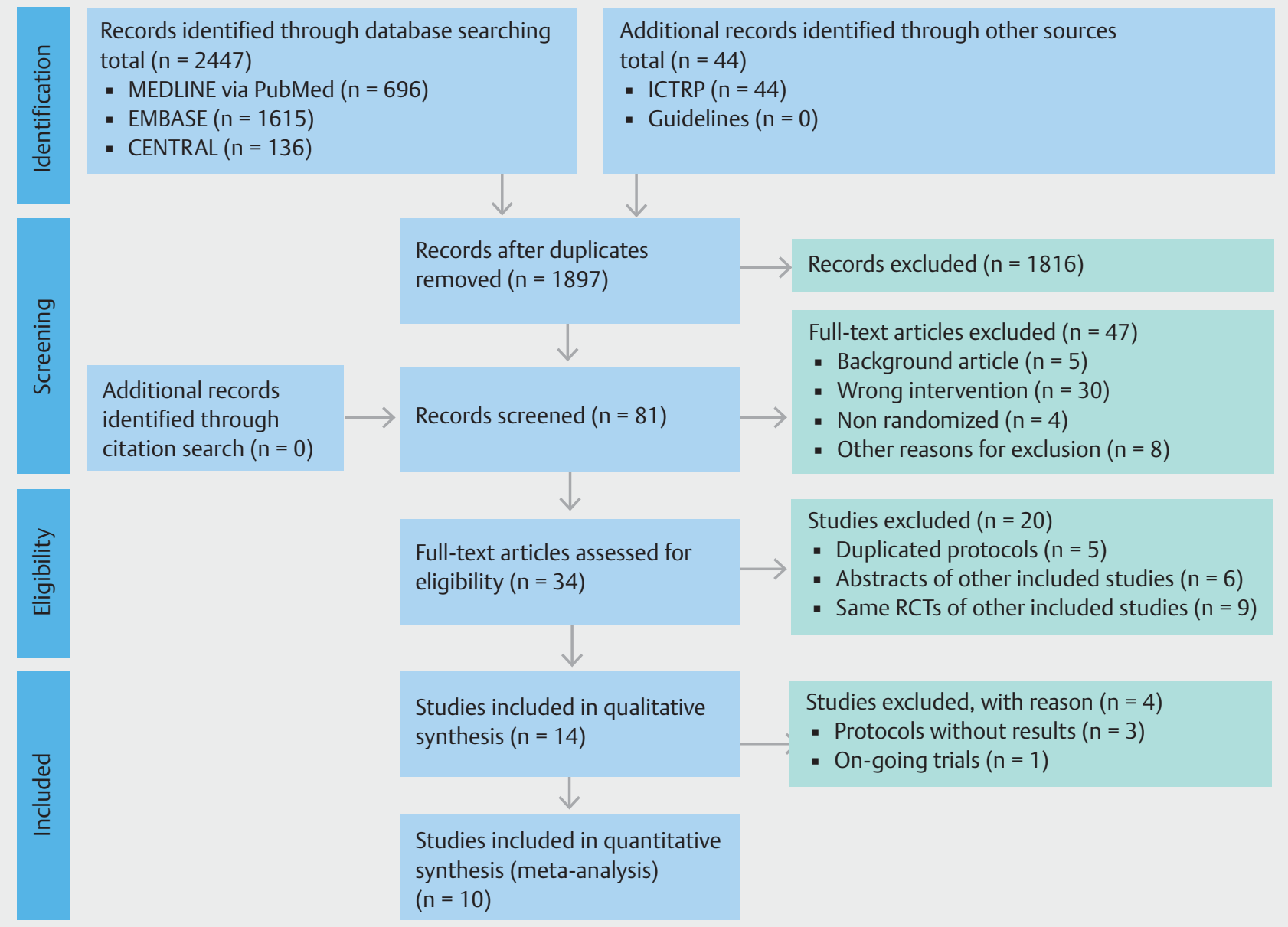

- Fig. 1 PRISMA flow diagram of the literature search results. From: Moher D, Liberati A, Tetzlaff J, Altman DG, The PRISMA Group (2009). Preferred Reporting Items for Systematic Reviews and Meta-Analyses: The PRISMA Statement. PLoS Med 6(7): e1000097. doi:10.1371/journal. pmed1000097

\section{Data synthesis}

We had decided in the protocol to perform a meta-analysis for the non-left lateral and left lateral starting position, but taking into account the clinical heterogeneity of the included RCT interventions, we performed the meta-analysis for the study of right lateral versus left lateral, supine versus left lateral, prone versus left lateral, tilt-down versus left lateral starting position during colonoscopy. We synthesized the data using Review Manager 5.3 (RevMan 2014) and used a random-effect model for meta-analysis. We interpreted random-effects meta-analyses with consideration to the whole distribution of effect and presented a $95 \%$ prediction interval (PI) [14].

\section{Subgroup analysis and investigation of heterogeneity}

We conducted the following subgroup analyses to examine the impact of bias risk and assessed the participants' heterogeneity in each study:

1. Sedation (participants with or without sedation); and

2. Imaging device (with or without imaging-guided insertion device)

\section{Sensitivity analysis}

We conducted the following prespecified sensitivity analyses for cecal insertion time, the proportion of successful cecal insertion, and the proportion of participants who need a position change:

1. Missing participants:

Best-best scenario: all missing patients in the two groups remained unchanged.

Best-worst scenario: all missing patients in the intervention group remained unchanged and all missing patients in the control group had outcomes.

Worst-best scenario: all missing patients in the intervention group had outcomes and all missing patients in the control group remained unchanged.

Primary analysis (worst-worst scenario: all missing patients in the two groups had outcomes).

2. Exclusion of studies that included colonoscopists who had not performed $\geq 200$ colonoscopy procedures [15].

3. Exclusion of studies using another definition of the mean cecal insertion time for colonoscopy. 


\begin{tabular}{|c|c|c|c|c|c|c|c|c|c|}
\hline 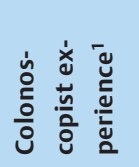 & 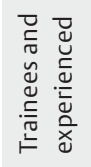 & $\tilde{z}$ & $\tilde{z}$ & $\tilde{z}$ & 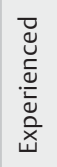 & 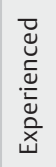 & 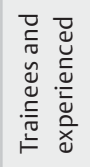 & $\tilde{z}$ & $\tilde{z}$ \\
\hline 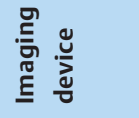 & 岳 & $\tilde{z}$ & $\tilde{z}$ & $\tilde{z}$ & $\tilde{z}$ & 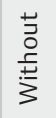 & $\stackrel{5}{\frac{1}{3}}$ & $\tilde{z}$ & $\tilde{z}$ \\
\hline 产 & 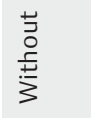 & $\Sigma \tilde{z}$ & $\tilde{z}$ & $\tilde{z}$ & $\Sigma$ & 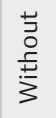 & 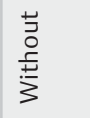 & $\tilde{z}$ & $\Sigma$ \\
\hline 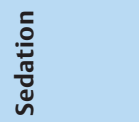 & $\frac{5}{3}$ & $\frac{E}{3}$ & $\stackrel{E}{\frac{E}{3}}$ & $\frac{E}{3}$ & 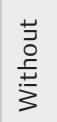 & 产 & 竍 & $\tilde{z}$ & $\tilde{z}$ \\
\hline
\end{tabular}
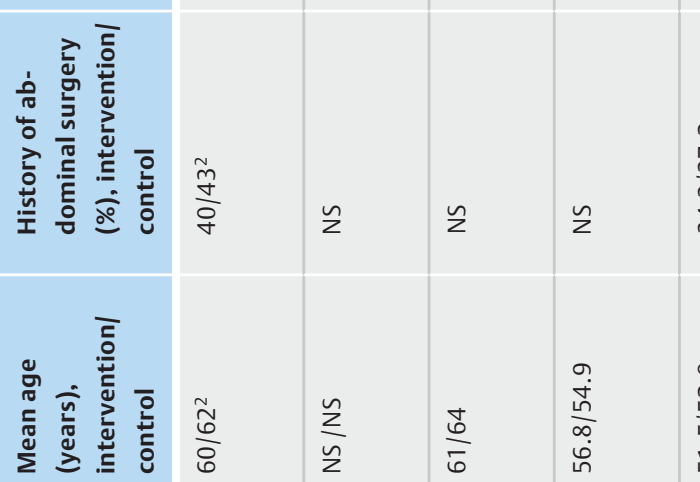

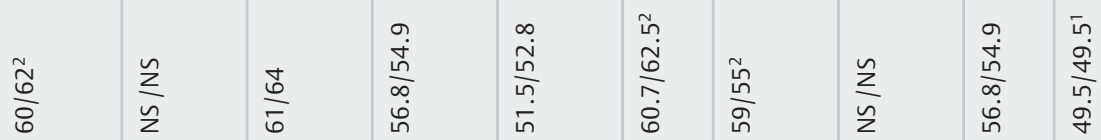

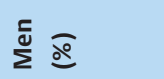

i

ìn
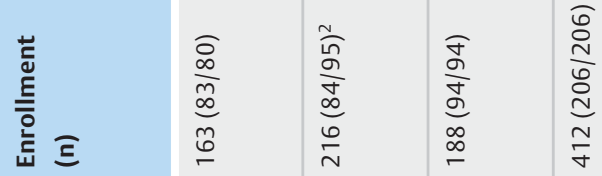

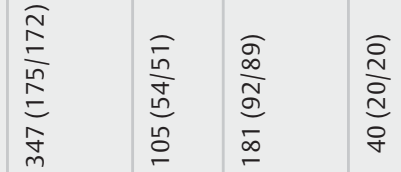

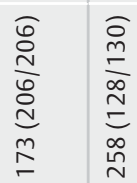

\begin{tabular}{|c|c|c|c|c|c|c|c|c|c|c|}
\hline 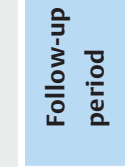 & 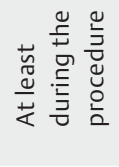 & 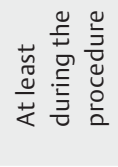 & 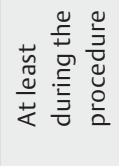 & 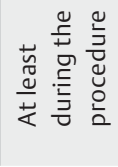 & 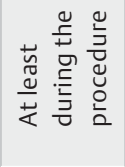 & $\begin{array}{l}\frac{n}{\sqrt{0}} \\
\text { m } \\
m\end{array}$ & 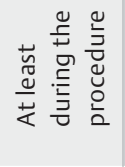 & 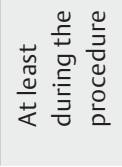 & $\begin{array}{l}\stackrel{n}{\sqrt{0}} \\
-\end{array}$ & 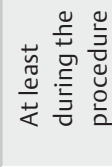 \\
\hline 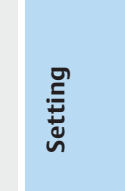 & 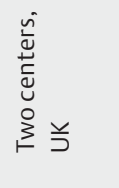 & 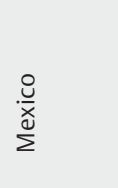 & 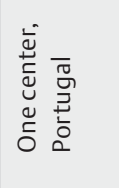 & 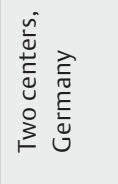 & 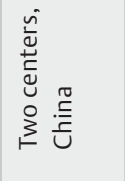 & 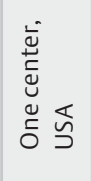 & 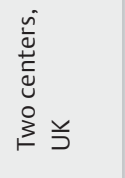 & 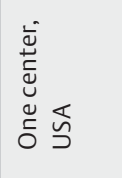 & 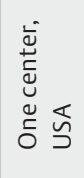 & 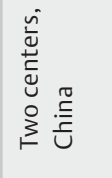 \\
\hline 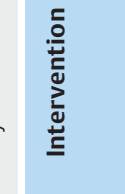 & 蒙 & $\begin{array}{l}\text { 蒙 } \\
\frac{\sigma}{\bar{\alpha}}\end{array}$ & $\begin{array}{l}\frac{\vec{\sigma}}{\bar{\sigma}} \\
\frac{\bar{\sigma}}{2}\end{array}$ & $\begin{array}{l}\stackrel{\mathscr{\Xi}}{\bar{a}} \\
\stackrel{\vec{n}}{n}\end{array}$ & 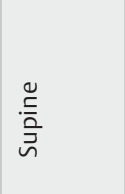 & 䒕 & 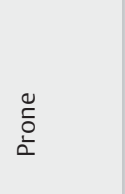 & 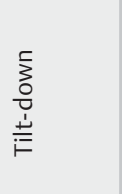 & 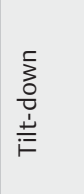 & 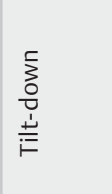 \\
\hline 剤 & 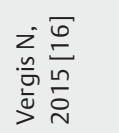 & 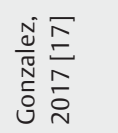 & 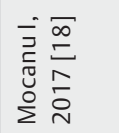 & 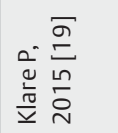 & 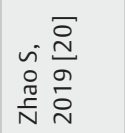 & 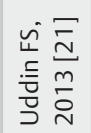 & 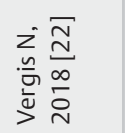 & 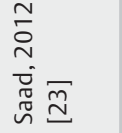 & 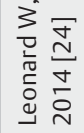 & 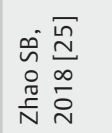 \\
\hline
\end{tabular}




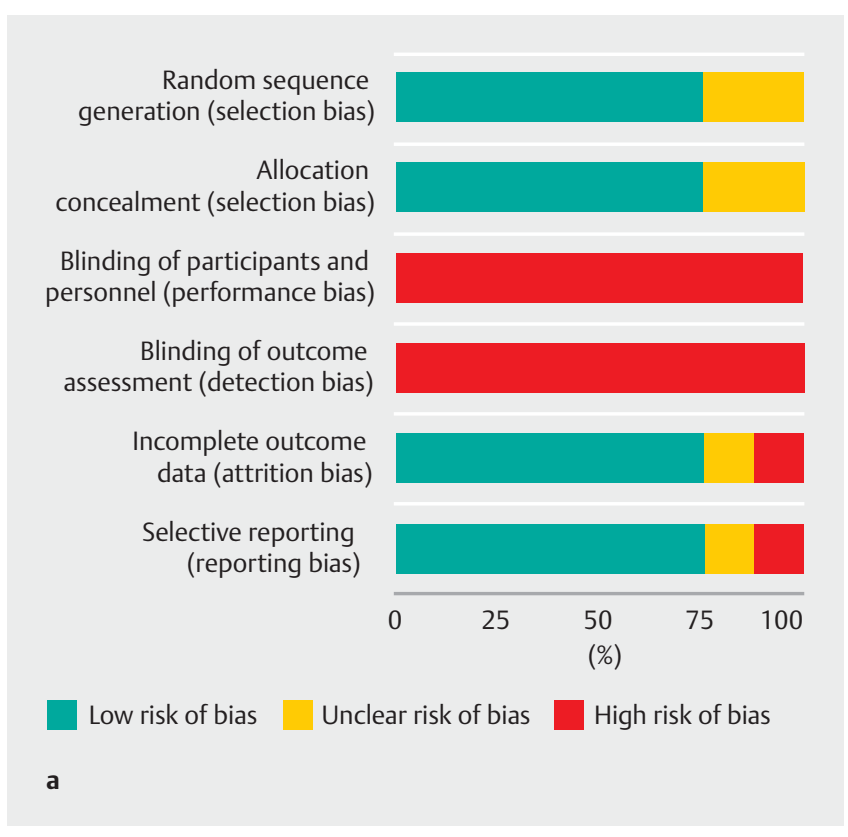

\section{Results}

\section{Characteristics of the included studies}

We identified 2447 records (MEDLINE 1615 records, EMBASE 1615 records, CENTRAL 136 records) until February 12, 2019.

- Fig. 1 shows the article selection process. After the duplicates were removed using Mendeley Desktop Software (www.mendeley.com, version 1.19.4), we screened 1897 records for inclusion and 14 trials met the inclusion criteria. Among the 14 trials, we identified 1 ongoing trial (NCT03489824), 3 protocols without results (NCT03337217, NCT03355495, and NCT00314418) and 10 clinical trials. We summarized and described the studies in $>$ Table 1 . We included 10 studies (with 2083 participants) that compared a starting position other than the left lateral with the left lateral starting position during colonoscopy [16-25].

\section{Risk of bias}

We present the risk of bias of each study in the "Risk of bias" tables in $>$ Fig. 2 and $>$ Fig. 3, and Appendix 3, Appendix 4, Appendix 5, Appendix 6, and Appendix 7.

\section{Primary outcomes}

\section{Mean cecal insertion time for colonoscopy}

Eight studies were eligible for the evaluation of the mean cecal insertion time for colonoscopy $[16,17,20-25]$. We identified two studies in right lateral versus left lateral position, one study in supine versus left lateral position, two studies in prone versus left lateral, and three studies in tilt-down versus left lateral position. The mean cecal insertion time for colonoscopy was statistically significantly shorter in the supine position (MD -41.0 s; -57.3 to -24.7$)$ in one study and tilt-down positions (MD $-37.3 \mathrm{~s} ;-72.1$ to $-2.4 ; \mathrm{I}^{2}=58 \% ; 95 \% \mathrm{PI}-72.3$ to -2.3 ) in three studies than in the left lateral position; however, there

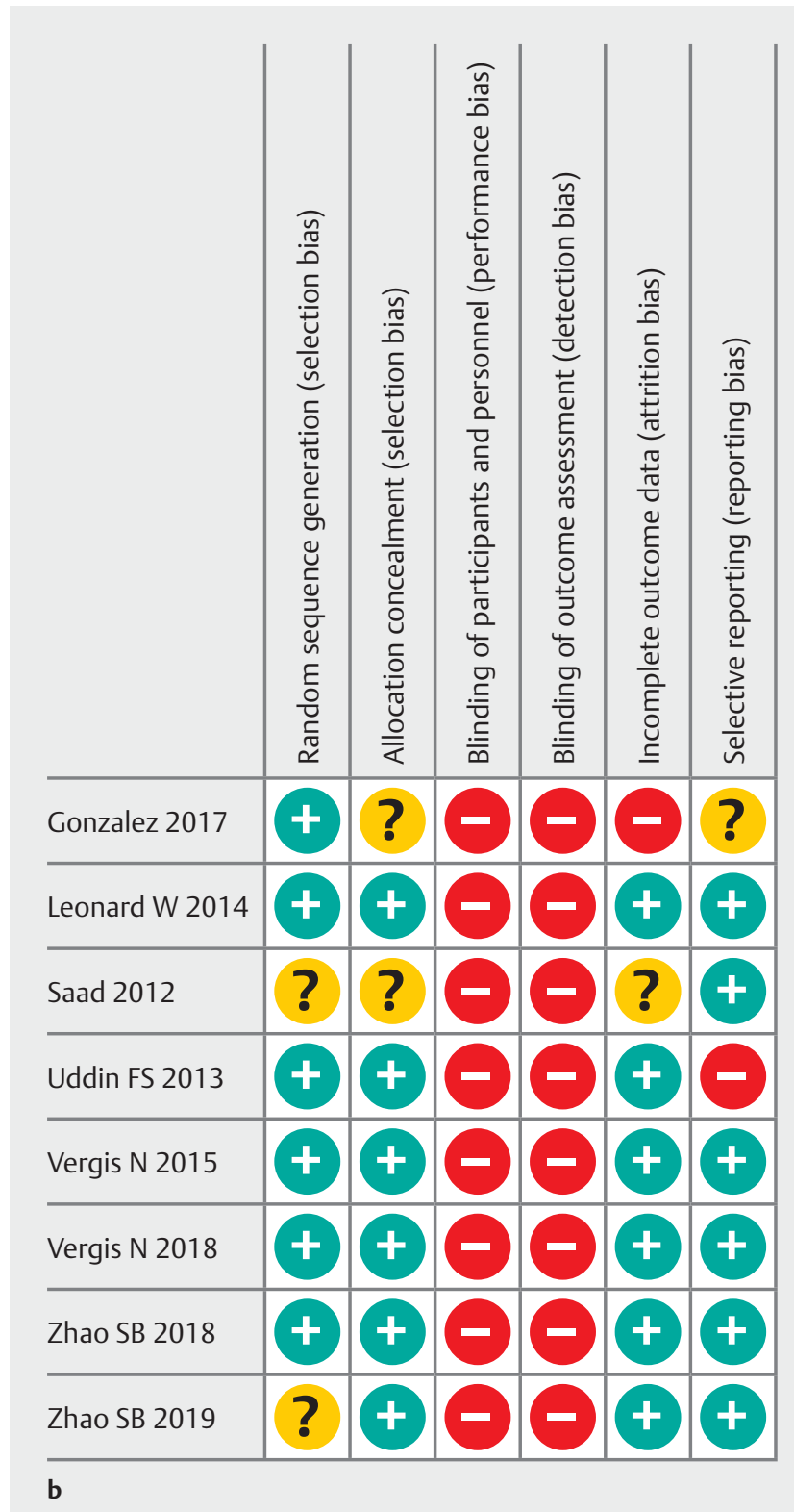

Fig. 2 Risk of bias graph and table for mean cecal insertion time.

were no statistically significant differences between the prone position in two studies (MD $-23.1 \mathrm{~s} ;-275.8$ to $322.0 ; \mathrm{I}^{2}=93 \%$; $95 \% \mathrm{PI}-322.2$ to 276.1 ) or right lateral position in two studies (MD -50.6s; -355.9 to $254.8 ; \mathrm{I}^{2}=91 \% ; 95 \% \mathrm{PI}-356.2$ to 255.0 ) than in the left lateral position ( $\mathbf{F i g} .3$ ). The certainty of the evidence for mean cecal insertion time for colonoscopy was very low.

\section{AEs requiring medication}

AEs were measured in eight studies [16,19-25]. There was one study in right lateral versus left lateral position, two studies in supine versus left lateral position, two studies in prone versus left lateral, and three studies in tilt-down versus left lateral position. Four studies reported no AEs: one study in right lateral versus left lateral, one study in supine versus left lateral, one 


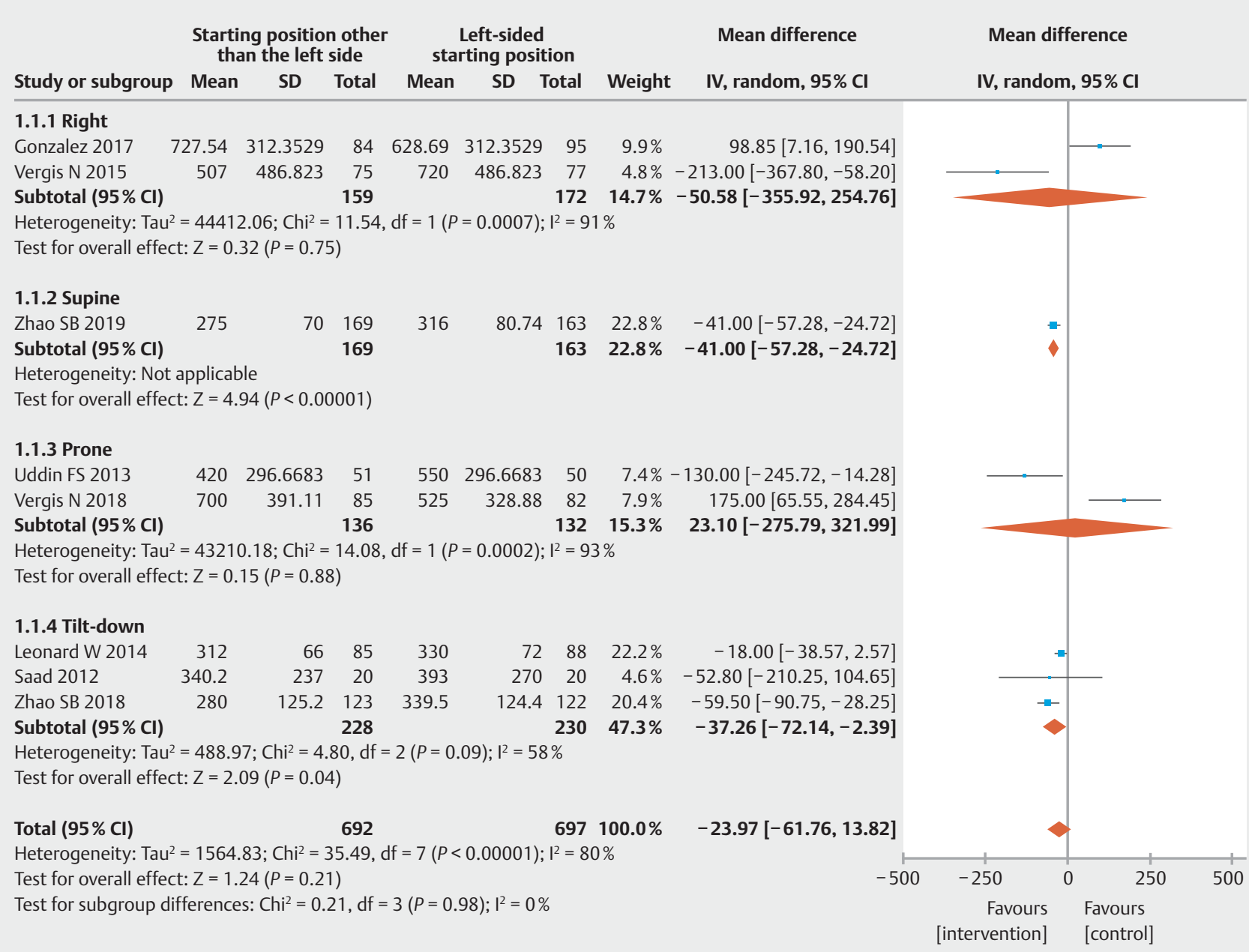

Fig. 3 Forest plot of mean cecal insertion time for colonoscopy at each starting position.

study in prone versus left lateral, and one study in tilt-down versus left lateral starting position ( $\mathbf{F i g . 4 )}[16,20,22,25]$. In the other four studies, of the 11 participants (1.3\%) who required medication in the non-left lateral starting position, one had post-polypectomy bleeding in prone position and nine in supine and one in tilt-down had oxygen desaturation (<90\%) requiring increased oxygen supplementation. On the other hand, of the 16 participants $(1.9 \%)$ requiring medication in the left lateral starting position, 14 had oxygen desaturation $(<90 \%)$ requiring increased oxygen supplementation, and 2 had bradycardia $[19,23,24]$. One RCT in the tilt-down versus left lateral starting position was terminated because of increased occurrence of oxygen desaturation [24]. There were no statistically significant differences for adverse events requiring medication between supine and left lateral (RR 0.75; 0.32 to 1.74 ), prone and left lateral (RR 2.94; 0.12 to 70.56 ), and tilt-down and left lateral (RR $0.36 ; 0.06$ to 2.27 ). The certainty of evidence for adverse effects was moderate.

\section{Secondary outcomes}

\section{Proportion of successful cecal insertion}

Seven studies were eligible for the evaluation of the proportion of successful cecal insertion [16, 19, 20,21,22, 24, 25]. We included one study in right lateral versus left lateral position, two studies in supine versus left lateral position, two studies in prone versus left lateral, and two studies in tilt-down versus left lateral position. The proportion of successful cecal insertion did not increase in right lateral (RR 0.94; 0.86 to 1.02 ;), supine (RR $1.01 ; 0.98$ to $1.04 ; I^{2}=0 ; 95 \%$ PI 0.98 to 1.04 ), prone (RR 0.96; 0.91 to $1.02 ; I^{2}=0 \% ; 95 \%$ PI 0.91 to 1.02 ), and tilt-down (RR $1.01 ; 0.97$ to $1.04 ; I^{2}=36 \%: 95 \%$ PI 0 to 2066.8 ) position compared with left lateral position ( $\mathbf{F i g . 5}$ ). Certainty of evidence for the proportion of successful cecal insertion was moderate. 


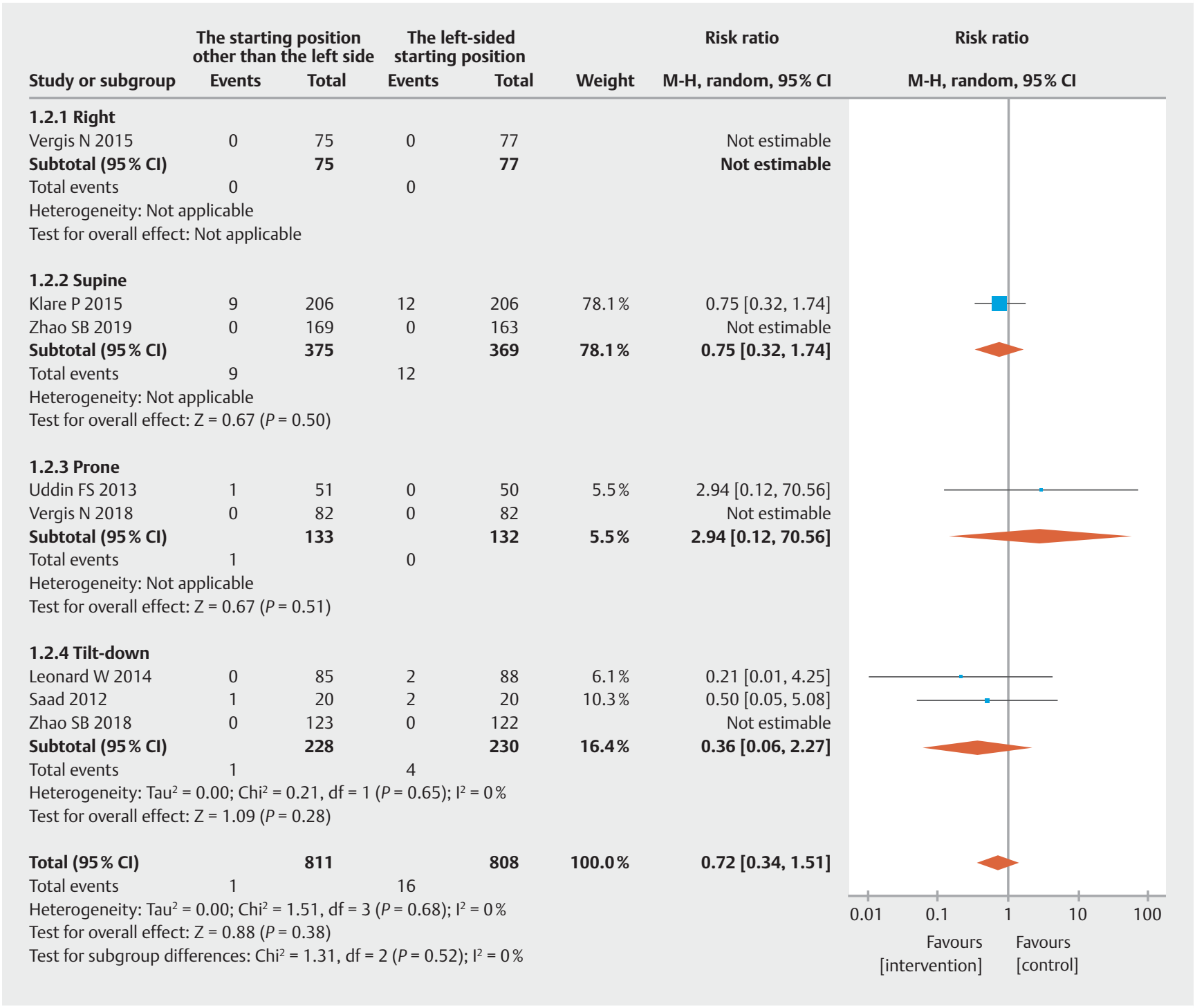

- Fig. 4 Forest plot of the proportion of adverse events requiring medication in each starting position.

\section{Proportion of participants who needed a position change}

Four studies were eligible for evaluation of the proportion of participants who needed a position change [19,20,21,25]. We identified one study in right lateral versus left lateral position, two studies in supine versus left lateral position, and one study in tilt-down versus left lateral position. The proportion of participants who needed a position change from the starting position during colonoscopy were smaller in right lateral position (RR $0.44 ; 0.20$ to 0.99 ), supine position (RR $0.39 ; 0.17$ to 0.93 ; $\mathrm{I}^{2}=90 \%$; $95 \% \mathrm{PI} 0$ to 69041.7 ), and tilt-down position (RR 0.72; 0.54 to 0.95 ) than in left lateral position ( $\mathbf{F i g . 6}$ ). The certainty of evidence for the proportion of participants who needed a position change was low.

\section{Mean score of the participant pain or discomfort}

Six studies were eligible for evaluation of the mean score of the participants' pain or discomfort [16, 20, 21, 22, 24, 25]. We included one study in right versus left position, one study in supine versus left position, two studies in prone versus left position, and one study in tilt-down versus left position. Each study on the right (SMD $-0.38 ;-0.70$ to -0.06 ) and supine (SMD $-0.36 ;-0.58$ to -0.15 ) positions reduced the participants' pain and discomfort; however, prone (SMD 0.02; -0.22 to $0.26 ; \mathrm{I}^{2}=0 \% ; 95 \% \mathrm{PI}-0.22$ to 0.26 ) and tilt-down (SMD $-1.73 ;-4.43$ to $0.96 ; \mathrm{I}^{2}=99 \%$; $95 \% \mathrm{PI}-14.7$ to 11.2 ) position did not reduce the participants' pain and discomfort compared with left position ( $\triangleright$ Fig. 7 ). The certainty of evidence for mean score of the participants' pain or discomfort was low. 


\begin{tabular}{|c|c|c|c|c|c|c|c|c|c|c|c|}
\hline \multirow{3}{*}{$\begin{array}{l}\text { Study or subgroup } \\
\text { 2.1.1 Right }\end{array}$} & \multicolumn{2}{|c|}{$\begin{array}{l}\text { Starting position } \\
\text { other than the left side }\end{array}$} & \multicolumn{2}{|c|}{$\begin{array}{c}\text { Left-sided } \\
\text { starting position }\end{array}$} & \multirow[b]{2}{*}{ Weight } & Risk ratio & \multicolumn{4}{|c|}{ Risk ratio } & \\
\hline & Events & Total & Events & Total & & $\mathrm{M}-\mathrm{H}$, random, $95 \% \mathrm{Cl}$ & \multicolumn{5}{|c|}{ M-H, random, $95 \% \mathrm{Cl}$} \\
\hline & & & & & & & & & & & \\
\hline Vergis N 2015 & 75 & 83 & 77 & 80 & $4.0 \%$ & $0.94[0.86,1.02]$ & & & & & \\
\hline Subtotal $(95 \% \mathrm{Cl})$ & & 83 & & 80 & $4.0 \%$ & $0.94[0.86,1.02]$ & & 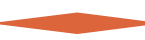 & & & \\
\hline Total events & 75 & & 77 & & & & & & & & \\
\hline \multicolumn{12}{|c|}{ Heterogeneity: Not applicable } \\
\hline \multicolumn{12}{|c|}{ Test for overall effect: $Z=1.50(P=0.13)$} \\
\hline \multicolumn{12}{|l|}{ 2.1.2 Supine } \\
\hline Klare P 2015 & 194 & 206 & 194 & 206 & $11.8 \%$ & $1.00[0.95,1.05]$ & & . & & & \\
\hline Zhao SB 2019 & 169 & 175 & 163 & 172 & $13.6 \%$ & $1.02[0.97,1.07]$ & & &. & & \\
\hline Subtotal (95\% Cl) & & 381 & & 378 & $25.4 \%$ & $1.01[0.98,1.04]$ & & & & & \\
\hline Total events & 363 & & 357 & & & & & & & & \\
\hline \multicolumn{12}{|c|}{ Heterogeneity: $\operatorname{Tau}^{2}=0.00 ; \mathrm{Chi}^{2}=0.32, \mathrm{df}=1(P=0.57) ; \mathrm{I}^{2}=0 \%$} \\
\hline \multicolumn{12}{|c|}{ Test for overall effect: $Z=0.60(P=0.55)$} \\
\hline \multicolumn{12}{|l|}{ 2.1.3 Prone } \\
\hline Uddin FS 2013 & 51 & 54 & 50 & 51 & $4.8 \%$ & $0.96[0.89,1.04]$ & & & — & & \\
\hline Vergis N 2018 & 82 & 92 & 82 & 89 & $3.1 \%$ & $0.97[0.88,1.06]$ & & & & & \\
\hline Subtotal $(95 \% \mathrm{Cl})$ & & 146 & & 140 & $7.9 \%$ & $0.96[0.91,1.02]$ & & & & & \\
\hline Total events & 133 & & 132 & & & & & & & & \\
\hline \multicolumn{12}{|c|}{ Heterogeneity: Tau $^{2}=0.00 ; \mathrm{Chi}^{2}=0.01, \mathrm{df}=1(P=0.94) ; \mathrm{I}^{2}=0 \%$} \\
\hline \multicolumn{12}{|c|}{ Test for overall effect: $Z=1.19(P=0.23)$} \\
\hline \multicolumn{12}{|l|}{ 2.1.4 Tilt-down } \\
\hline Leonard W 2014 & 85 & 85 & 88 & 88 & $54.0 \%$ & $1.00[0.98,1.02]$ & & & & & \\
\hline Zhao SB 2018 & 123 & 128 & 122 & 130 & $8.6 \%$ & $1.02[0.97,1.08]$ & & & & & \\
\hline Subtotal $(95 \% \mathrm{Cl})$ & & 213 & & 218 & $62.7 \%$ & $1.01[0.97,1.04]$ & & & & & \\
\hline Total events & 208 & & 210 & & & & & & & & \\
\hline \multicolumn{12}{|c|}{ Heterogeneity: $\mathrm{Tau}^{2}=0.00 ; \mathrm{Chi}^{2}=1.57, \mathrm{df}=1(P=0.21) ; \mathrm{I}^{2}=36 \%$} \\
\hline \multicolumn{12}{|c|}{ Test for overall effect: $Z=0.37(P=0.71)$} \\
\hline Total $(95 \% \mathrm{Cl})$ & & 823 & & 816 & $100.0 \%$ & $1.00[0.98,1.02]$ & & & & & \\
\hline Total events & 779 & & 776 & & & & & & & & \\
\hline \multicolumn{12}{|c|}{ Heterogeneity: $\mathrm{Tau}^{2}=0.00 ; \mathrm{Chi}^{2}=5.21, \mathrm{df}=6(P=0.52) ; \mathrm{I}^{2}=0 \%$} \\
\hline \multicolumn{7}{|c|}{ Test for overall effect: $Z=0.09(P=0.93)$} & 0.85 & 0.9 & 1 & 1.1 & 1.2 \\
\hline \multicolumn{7}{|c|}{ Test for subgroup differences: $\mathrm{Chi}^{2}=4.13, \mathrm{df}=3(P=0.25) ; \mathrm{I}^{2}=27.4 \%$} & & $\begin{array}{r}\text { Favours } \\
\text { [control] }\end{array}$ & $\begin{array}{l}\text { Favo } \\
\text { [inte }\end{array}$ & $\begin{array}{l}\text { ours } \\
\text { ervention] }\end{array}$ & \\
\hline
\end{tabular}

- Fig. 5 Forest plot of the proportion of successful cecal insertion after the primary colonoscopy procedure in each starting position.

Proportion of AEs due to sedatives/analgesics used and procedure-related complications

In the right lateral starting position, there were no complications $[16,17]$. In the supine starting position, 25 patients desaturated to $<90 \%$, nine patients needed increased oxygen supplementation, 33 patients had apnea and abnormal ventilation, 23 patients had bradycardia, and 6 patients had hypotension $[19,20]$. In the prone starting position, one patient had postpolypectomy bleeding $[21,22]$. In the tilt-down starting position, 10 patients desaturated to $<90 \%[23,24]$ and 1 patient needed increased oxygen supplementation [23]. In the left lateral starting position, 18 patients desaturated to $<90 \%[19,23$, 24], 14 patients needed increased oxygen supplementation [19,23], 19 patients had apnea and abnormal ventilation [19], 27 patients had bradycardia [19], and 25 patients had hypotension [19].
We could not perform prespecified subgroup analysis and all sensitivity analysis for cecal insertion time, the proportion of successful cecal insertion, and proportion of participants who need a position change ( $\triangleright$ Table 2 ). 


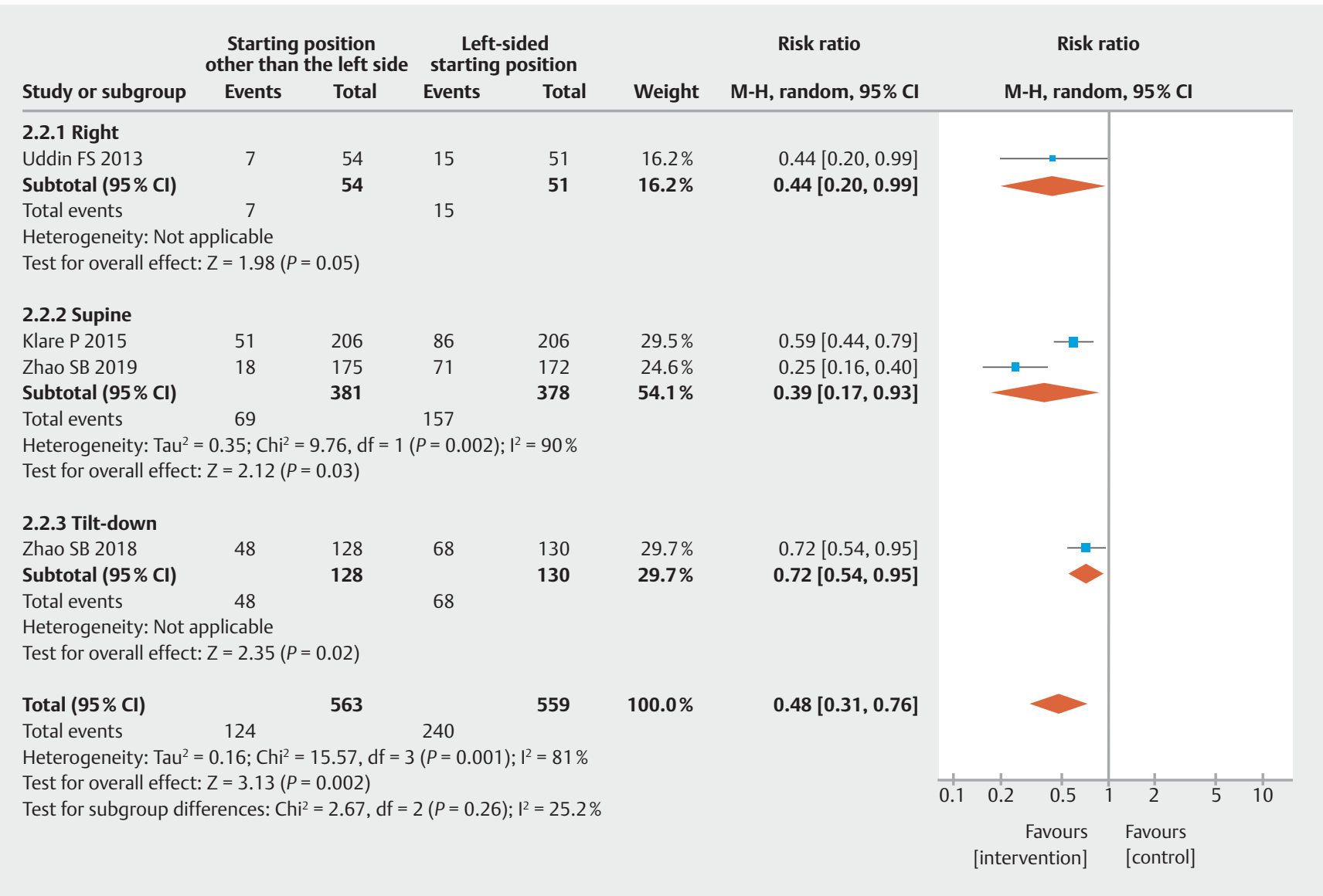

Fig. 6 Forest plot of the proportion of participants who needed a position change from the starting position during colonoscopy in each starting position.

\section{Discussion}

This review included 10 RCTs and 2,083 participants and we did not achieve any conclusions about the efficacy and safety of starting position during colonoscopy. Each starting position showed that the supine and tilt-down position reduced mean cecal insertion time for colonoscopy compared with the left lateral position. However, this data should be interpreted with caution because of a very low certainty of evidence. This is the first systematic review focused on assessing the efficacy and safety of the starting position during colonoscopy.

The supine and tilt-down starting positions might enable a shorter mean cecal insertion time and lesser need for a position change from the starting position during colonoscopy than the left lateral starting position [19, 20,23-25]. In addition, the supine position reduced the participants' pain [20]. Although there were no statistically significant differences in the proportion of successful cecal insertion between the supine and tiltdown position and left lateral starting positions during colonoscopy, the left lateral starting position increased the requirement for a position change. However, even if the position was changed very quickly according to the colonoscopist's or patient's preference, the patients still received the intervention to which they had been randomized. In addition, poor bowel preparation and/or female sex could affect the cecal insertion time because bowel preparation and subgroup analysis according to sex was not evaluated in the included studies on the supine and tilt-down starting positions [26]. Furthermore, as it can be difficult to find the location of the anus with the nonleft starting position, colonoscopists needed to first to find the anus in some patients [20].

If patients can tolerate colonoscopy without sedation, the non-left lateral starting position without sedation during colonoscopy may improve the cecal insertion time and reduce the adverse events. Previous studies reported that there was no difference in ADR between colonoscopy with and without sedation $[27,28]$. Colonoscopy with sedation resulted in a shorter cecal insertion time than colonoscopy under conscious sedation in a previous study [29]. In our review, the supine and tiltdown positions without sedation during colonoscopy decreased the cecal insertion time compared with the left lateral starting position without sedation $[20,25]$. However, adequate withdrawal time was more important for ADR [30]. Colonoscopy without sedation decreases the AEs [31]. In our review, there were no severe adverse events in the supine starting position with and without sedation $[19,20]$, but the supine position with sedation resulted in a higher rate of oxygen desaturation than the left position [19]. One RCT applying the tilt-down position was terminated because of the increased episodes of oxy- 


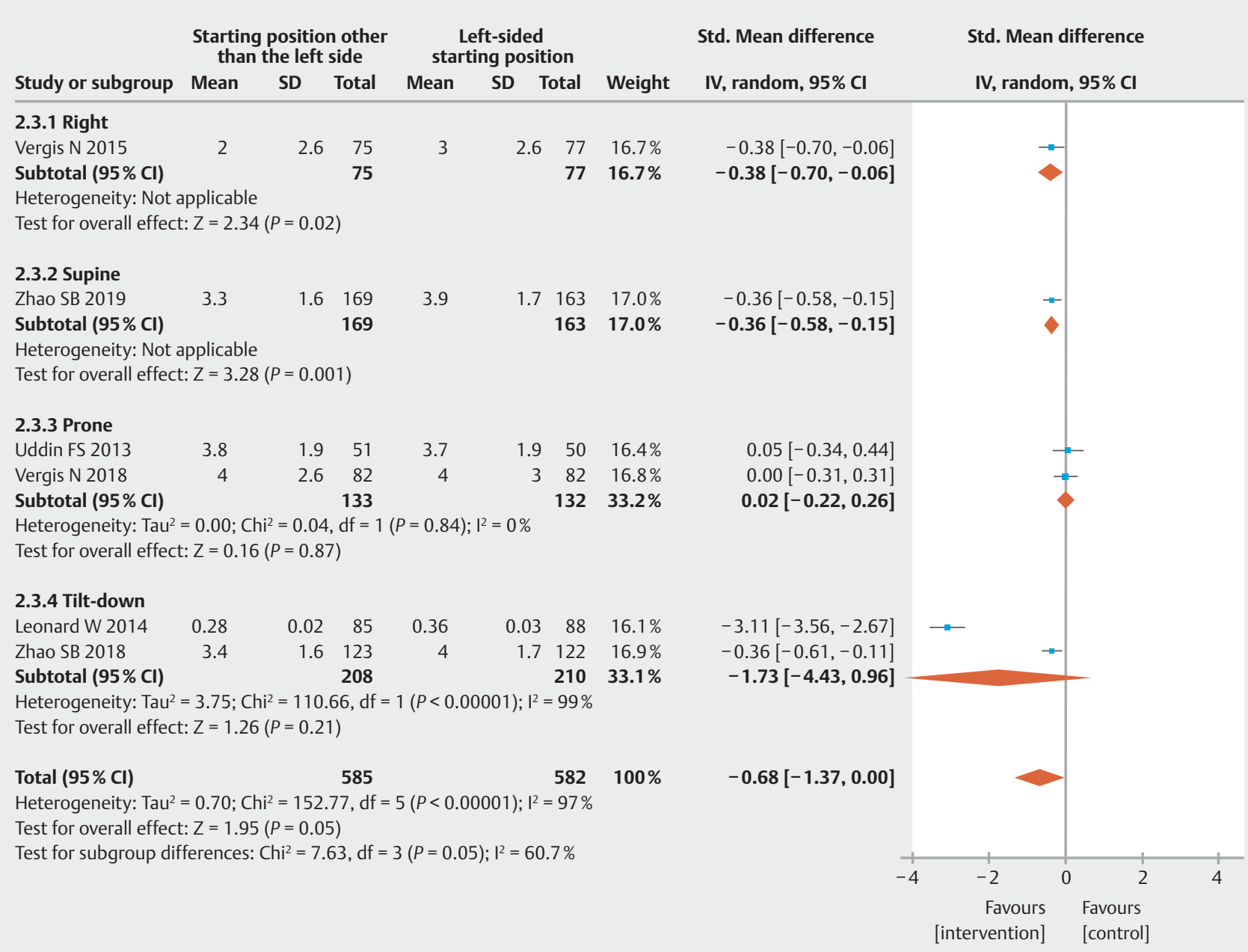

Fig. 7 Forest plot of the mean score of participant pain or discomfort in each starting position.

gen desaturation [24]. However, there were no adverse events in the tilt-down starting position without sedation [25]. Previous studies reported that colonoscopy without sedation decreases patients' satisfaction and increases pain [27,29]. In our review, the supine and tilt-down positions without sedation during colonoscopy decreased the participants' pain and increased the patients' acceptance of colonoscopy without sedation $[20,25]$. However, the studies included in our review did not rule out other factors besides the starting position during colonoscopy (such as water infusion colonoscopy, which reduced procedure-related abdominal pain) that could affect the participants' pain [32].

The current review has several potential limitations. First, performance and detection biases could not be excluded because the colonoscopists and participants in all included studies could not be masked. Second, although we reviewed median cecal insertion time as mean cecal insertion time for colonoscopy following the recommendation in the Cochrane handbook [14], the above approach would be biased due to skewed distribution. Third, we could not assess the participants' body mass index and medication usage.

\section{Conclusion}

In conclusion, our systematic review demonstrated that no definitive conclusion was reached regarding the efficacy and safety of starting position during colonoscopy. The findings imply that the decision with regard to the participant's position should be made after evaluating the overall clinical scenario and colonoscopist and patient preference. Further investigations are needed to assess the efficacy and safety of the starting position, especially the supine and tilt-down starting positions without sedation.

\section{Acknowledgements}

The authors thank Dr. Putut Bayupurnama, Dr. Nikhil Vergis, and Dr. Linda A. Feagins for providing us with additional information about their studies. We are grateful to Dr. Katsuro Ichimasa for giving us advice about the manuscript. 
$\checkmark$ Table2 Summary of findings.

\section{Starting position other than the left side compared with the left-sided starting position during colonoscopy}

\section{Patient or population: individuals undergoing colonoscopy}

Setting: any

Intervention: starting position other than the left side

Comparison: left-sided starting position

\begin{tabular}{|c|c|c|c|}
\hline Outcomes & Effect & $\begin{array}{l}\text { No. of participants } \\
\text { (studies) }\end{array}$ & $\begin{array}{l}\text { Certainty of the evidence } \\
\text { (GRADE) }\end{array}$ \\
\hline Mean cecal insertion time & $\begin{array}{l}\text { The supine and tilt-down position slightly } \\
\text { reduced cecal insertion time and the prone } \\
\text { and right position had no effect compared } \\
\text { with left lateral position. }\end{array}$ & $\begin{array}{l}1386 \\
\text { (8 RCTs) }\end{array}$ & $\begin{array}{l}\oplus O O O \\
\text { VERY LOW } \\
1,2,3\end{array}$ \\
\hline $\begin{array}{l}\text { Adverse events requiring medica- } \\
\text { tion }\end{array}$ & $\begin{array}{l}\text { Eight studies showed proportion of ad- } \\
\text { verse events requiring medication were al- } \\
\text { most the same. }\end{array}$ & $\begin{array}{l}1619 \\
\text { (8 RCTs) }\end{array}$ & $\begin{array}{l}\oplus \oplus \oplus O \\
\text { MODERATE }{ }^{1}\end{array}$ \\
\hline $\begin{array}{l}\text { The proportion of successful cecal } \\
\text { insertion }\end{array}$ & $\begin{array}{l}\text { Eight studies showed proportion of cecal } \\
\text { insertion was almost the same. }\end{array}$ & $\begin{array}{l}1639 \\
\text { (7 RCTs) }\end{array}$ & $\begin{array}{l}\oplus \oplus \oplus \circ \\
\text { MODERATE } 1\end{array}$ \\
\hline $\begin{array}{l}\text { The proportion of participants who } \\
\text { needed a position change }\end{array}$ & $\begin{array}{l}\text { Four studies in right, supine, and tilt-down } \\
\text { position showed small reductions in posi- } \\
\text { tion change. }\end{array}$ & $\begin{array}{l}1310 \\
(4 \text { RCTs) }\end{array}$ & $\begin{array}{l}\oplus \oplus \circ \bigcirc \\
\text { LOW }^{1,2}\end{array}$ \\
\hline $\begin{array}{l}\text { Score of the participants' pain or } \\
\text { discomfort } \\
\text { assessed with a visual analog scale } \\
\text { or a numeric rating scale }\end{array}$ & $\begin{array}{l}\text { The right and tilt-down position slightly } \\
\text { reduced participants' pain or discomfort. } \\
\text { Prone and tilt-down position had no effect } \\
\text { compared with left lateral position. }\end{array}$ & $\begin{array}{l}1167 \\
\text { (6 RCTs) }\end{array}$ & $\begin{array}{l}\oplus \oplus \circ \bigcirc \\
\mathrm{LOW}^{1,2}\end{array}$ \\
\hline Adverse events & $\begin{array}{l}\text { Four studies reported no adverse events. } \\
\text { The other four studies reported adverse } \\
\text { events. }\end{array}$ & $\begin{array}{l}1619 \\
\text { (8 RCTs) }\end{array}$ & $\begin{array}{l}\oplus \oplus \oplus \circ \\
\text { MODERATE }{ }^{1}\end{array}$ \\
\hline $\begin{array}{l}\text { RCT, randomized controlled trial; GRADE } \\
\text { GRADE Working Group grades of evide } \\
\text { High certainty: We are very confident } t \\
\text { Moderate certainty: We are moderately } \\
\text { it is substantially different. } \\
\text { Low certainty: Our confidence in the ef } \\
\text { Very low certainty: We have very little } \\
{ }^{1} \text { Downgraded because of imprecision d } \\
{ }^{2} \text { Downgraded because of inconsistency } \\
{ }^{3} \text { Downgraded because of risk of bias du }\end{array}$ & $\begin{array}{l}\text { ading of Recommendations, Assessment, Develop } \\
\text { he true effect lies close to that of the estimate of } \\
\text { fident in the effect estimate. The true effect is likel } \\
\text { estimate is limited. The true effect may be substa } \\
\text { dence in the effect estimate. The true effect is lik } \\
\text { the small sample size. } \\
\text { there was represent substantial heterogeneity } \\
\text { kewed distribution }\end{array}$ & $\begin{array}{l}\text { th, and Evaluation. } \\
\text { effect. } \\
\text { be close to the estimate } \\
\text { Ily different from the est } \\
\text { o be substantially differ }\end{array}$ & $\begin{array}{l}\text { effect, but there is a possibility that } \\
\text { of the effect. } \\
m \text { the estimate of effect. }\end{array}$ \\
\hline
\end{tabular}

\section{Competing interests}

The authors declare that they have no conflict of interest.

\section{References}

[1] Winawer S], Zauber AG, Ho MN et al. Prevention of colorectal cancer by colonoscopic polypectomy. The National Polyp Study Workgroup. N Engl J Med 1993; 329: 1977-1981

[2] Zauber AG, Winawer SJ, O'Brien MJ et al. Colonoscopic polypectomy and long-term prevention of colorectal-cancer deaths. N Engl J Med 2012; 366: 687-696

[3] Siegel RL, Miller KD, Jemal A. Cancer statistics, 2019. CA Cancer J Clin 2019; 69: 7-34

[4] Peery AF, Dellon ES, Lund J et al. Burden of gastrointestinal disease in the United States: 2012 update. Gastroenterology 2012; 143: 11791187

[5] Kravochuck S, Gao R, Church J. Differences in colonoscopy technique impact quality. Surg Endosc 2014; 28: 1588-1593
[6] Rex DK, Schoenfeld PS, Cohen J et al. Quality indicators for colonoscopy. Am J Gastroenterol 2015; 110: 72-90

[7] Rembacken B, Hassan C, Riemann JF et al. Quality in screening colonoscopy: position statement of the European Society of Gastrointestinal Endoscopy (ESGE). Endoscopy 2012; 44: 957-968

[8] Cappell MS, Friedel D. The role of sigmoidoscopy and colonoscopy in the diagnosis and management of lower gastrointestinal disorders: technique, indications, and contraindications. Med Clin North Am 2002; 86: 1217-1252

[9] Arya V, Singh S, Agarwal S et al. Position change during colonoscopy improves caecal intubation rate, mucosal visibility, and adenoma detection in patients with suboptimal caecal preparation. Prz Gastroenterol 2017; 12: 296-302

[10] Lee A, Iskander JM, Gupta $\mathrm{N}$ et al. Queue position in the endoscopic schedule impacts effectiveness of colonoscopy. Am J Gastroenterol 2011; 106: 1457-1465

[11] Liberati A, Altman DG, Tetzlaff J et al. The PRISMA statement for reporting systematic reviews and meta-analyses of studies that evaluate health care interventions: explanation and elaboration. PLoS Med 2009; 6: e1000100 
[12] Kaminski MF, Thomas-Gibson S, Bugajski M et al. Performance measures for lower gastrointestinal endoscopy: a European Society of Gastrointestinal Endoscopy (ESGE) Quality Improvement Initiative. Endoscopy 2017; 49: 378-397

[13] Rex DK, Boland CR, Dominitz JA et al. Colorectal cancer screening: recommendations for physicians and patients from the U.S. Multi-society Task Force on Colorectal Cancer. Gastroenterology 2017; 153: 307-323

[14] Higgins JPT, Green S. Cochrane handbook for systematic reviews of interventions, version 5.1.0. 2011: https://handbook-5-1.cochrane. org [Accessed 29 September 2019]

[15] Atkin W, Rogers P, Cardwell C et al. Wide variation in adenoma detection rates at screening flexible sigmoidoscopy. Gastroenterology 2004; 126: 1247-1256

[16] Vergis N, McGrath AK, Stoddart CH et al. Right Or Left in COLonoscopy (ROLCOL)? A randomized controlled trial of right- versus left-sided starting position in colonoscopy Am J Gastroenterol 2015; 110: 1576-1581

[17] Gonzalez FM, Bueno N, Casillas GB et al. Comparison between conventional left lateral position and right lateral position as the starting position in colonoscopy. Gastrointest Endosc 2017; 85: AB179AB180

[18] Mocanu I, Laranjo A, Pires S et al. Colonoscopy on the left, right? U Eur Gastroenterol J 2017; 5: A461

[19] Klare P, Huth R, Haller B et al. Patient position and hypoxemia during propofol sedation for colonoscopy: a randomized trial. Endoscopy 2015; 47: 1159-1166

[20] Zhao S, Yang X, Meng Q et al. Impact of the supine position versus left horizontal position on colonoscopy insertion: a 2-center, randomized controlled trial. Gastrointest Endosc 2019; 89: 1193-1201.e1

[21] Uddin FS, Iqbal R, Harford WV et al. Prone positioning of obese patients for colonoscopy results in shortened cecal intubation times: a randomized trial. Dig Dis Sci 2013; 58: 782-787
[22] Vergis N, Scarborough A], Morris JA et al. Prone or left for colonoscopy? A randomized controlled trial of prone versus left-sided starting position for colonoscopy J Clin Gastroenterol 2018; 52: e82-e86

[23] Saad AM, Winn J, Chennamaneni $V$ et al. The value of the Trendelenburg position during routine colonoscopy: a pilot study. Gastroenterology 2012; 142: S229

[24] Leonard W. Evaluate the safety and diagnostic advantages of tilt down verses standard horizontal colonoscopy positioning (CTDTTIE). 2014: https://clinicaltrials.gov/ct2/show/results/NCT01815671? view=results [Accessed 29 September 2019]

[25] Zhao SB, Yang X, Fang J et al. Effect of left lateral tilt-down position on cecal intubation time: a 2-center, pragmatic, randomized controlled trial. Gastrointest Endosc 2018; 87: 852-861

[26] Jaruvongvanich $V$, Sempokuya $T$, Laoveeravat $P$ et al. Risk factors associated with longer cecal intubation time: a systematic review and meta-analysis. Int J Colorectal Dis 2018; 33: 359-365

[27] Bannert C, Reinhart K, Dunkler D et al. Sedation in screening colonoscopy: impact on quality indicators and complications. Am J Gastroenterol 2012; 107: 1837-1848

[28] Metwally M, Agresti N, Hale WB et al. Conscious or unconscious: the impact of sedation choice on colon adenoma detection. World ] Gastroenterol 2011; 17: 3912-3915

[29] Nakshabendi R, Berry AC, Munoz JC et al. Choice of sedation and its impact on adenoma detection rate in screening colonoscopies. Ann Gastroenterol 2016; 29: 50-55

[30] Jung Y, Joo YE, Kim HG et al. Relationship between the endoscopic withdrawal time and adenoma/polyp detection rate in individual colonic segments: a KASID multicenter study. Gastrointest Endosc 2019; 89: 523-530

[31] Cooper GS, Kou TD, Rex DK. Complications following colonoscopy with anesthesia assistance: a population-based analysis. JAMA Intern Med 2013; 173: 551-556

[32] Hafner S, Zolk K, Radaelli F et al. Water infusion versus air insufflation for colonoscopy. Cochrane Database Syst Rev 2015: 05CD009863 